\title{
Strategic Planning in Practice: The Case of Utah's Statewide Strategic Plan on Homelessness
}

\author{
Lina Svedin $^{1}$ a, Jesus N. Valero ${ }^{1 b}$ \\ ${ }^{1}$ Political Science, University of Utah \\ Keywords: focus group research, community engaged research, community partnerships, homeless policy, strategic planning \\ https://doi.org/10.35844/001c.13294
}

Journal of Participatory Research Methods

Vol. 1, Issue 1, 2020

\begin{abstract}
Much has been written theoretically about the concept and process of strategic planning. However, less is written in the scholarship about the nuts and bolts of strategic planning such as experiences in the practice of community engaged research to develop plans that achieve strategic change. In this study, we reflect on a recent partnership with a public agency to draft a statewide strategic plan on homelessness and we outline in detail the process that we undertook to build the partnership and engage in community-focused and driven research. After engaging in a reflective exercise, we construct a three-phase process of strategic planning that was informed by both the existing literature and the nature of the community engaged partnership with the public agency.
\end{abstract}

\section{Introduction}

Homelessness is a complex human condition that continues to challenge communities across the United States. The most recent data from the U.S. Department of Housing and Urban Development (HUD) indicates that approximately 567,715 individuals experienced homelessness at one point in $2019^{1}$. It is well understood that the causes of homelessness are multidimensional and that individuals experiencing homelessness often need more than just housing support. At the same time, there is a strong realization that homelessness can, and should, be tackled in a coordinated effort involving stakeholders from all sectors, including government agencies, nonprofit groups, and other private entities. The most recent federal strategic plan on homelessness, Home Together, acknowledges that "solutions are going to take all of us working together, doing our parts, strengthening our communities." In addition, the federal law governing federally-funded homeless programs and services through HUD's Continuum of Care Program calls for the creation of community-wide plans that pool local resources and input to tackle homelessness. Building consensus among multiple organizations can be a challenging process as any community plan requires an investment of resources and support towards solutions that may not directly benefit any one

\footnotetext{
a lina.svedin@utah.edu

b Corresponding author: jesus.valero@utah.edu

1 CoC Homeless Populations and Subpopulations Reports. Retrieved from https://www.hudexchange.info/programs/coc/coc-homelesspopulations-and-subpopulations-reports/
} 
organization. However, strategic plans can help organizations and communities bridge divides by forging a vision for the future that is inclusive and that supports diverse needs.

While much has been written about what strategic planning is and what its impact on performance theoretically is, less is known about the nuts and bolts of actually undertaking community-engaged strategic planning. This article responds to this gap with a case study detailing how a state recently approached developing a statewide strategic plan on homelessness. The article highlights the processes of building an interdisciplinary team to engage local communities in research and developing community-centric strategies to reduce homelessness. The sections that follow in this paper provide a brief overview of the literature on strategic planning and homeless policy in the U.S. The main body of the article discusses, step by step, how we linked key elements of strategic change processes with an interdisciplinary community-engaged research process to produce a statewide strategic plan on homelessness. The conclusions point to the theoretical and practical links between this case study and prior research as well as to some of this case's unique features.

\section{Literature Review}

\section{Strategic Planning}

There are indications that strategic planning has become a common form of strategic management within both government agencies and nonprofit organizations (Bryson et al., 2010). The Government Performance and ResIults Act of 1993, for instance, requires that federal agencies submit a strategic plan outlining goals and activities covering at least five years to the Director of the Office of Management and Budget and to Congress. Broadly defined, strategic planning refers to the practice of articulating an agency's mission and vision for the future and identifying the set of activities and efforts necessary to achieve associated goals. Bryson (2011) specifically defines strategic planning as "deliberative, disciplined approach to producing fundamental decisions and actions that shape and guide what an organization (or other entity) is, what it does, and why" (p. 7-8).

Creating a strategic plan means being intentional about the deliberate allocation of time, resources, and energy toward common goals and objectives.

In their review of prior research and planning models, Poister and Streib (2005) note that strategic planning often involves "clarifying mission and values, developing a vision of the future, analyzing external challenges and opportunities, assessing internal strengths and weaknesses, developing strategic goals and objectives, identifying strategic issues, developing and evaluating alternative strategies, and developing action plans” (p. 46). Ultimately, strategic plans are about action steps to create change within an organization and beyond, and thus, any plan requires a carefully crafted and articulated plan of implementation.

Based on previous research and evidence from practice, Bryson (2018) developed a carefully crafted framework of strategic planning that he dubbed the Strategy Change Cycle. The strategic planning process we engaged in 
married key features of the Strategy Change Cycle with community-engaged research processes, including the needs and preferences of our public agency partner. Bryson's cycle is really a 10-step process that begins with achieving an initial agreement to an assessment of the strategy and planning process. The first step of initiating and agreeing on a planning process focuses on securing the buy-in of key stakeholder groups and coming to an agreement on the process that will be used to generate the strategic plan. The second step, identifying organizational mandates, involves assessing formal and informal expectations that may place constraints on the strategic planning process such as policies or regulations, organizational bylaws, and informal rules set by existing politics. The third step is clarifying the organization's mission and values - a process that allows organizations to articulate the reason for their existence and the values they hope to embrace, which ultimately help rally stakeholders towards a common goal in the strategic planning process. The fourth and fifth steps involve assessing the organization's external and internal environments and identifying strategic issues, respectively. The sixth step is ultimately focused on developing strategies and plans that help address the strategic issues that were identified and help the organization achieve its mission. The final stages of the strategic change cycle include: adopting the strategies and plan, adopting a vision for the future, developing an effective implementation process, and reassessing the strategies and the planning process.

Bryson (2011) notes, however, that this process is a conceptual map and a "generic reference approach - and not the strategic planning process design that will be negotiated during the initial agreement step" (p. 67). The strategic planning process will vary depending on local conditions, needs of the organization, resources available, and the deliberative process adopted. Still, Bryson's (2018) conceptual framework is clear about the importance of stakeholder engagement, having a champion of the process, understanding the mission and vision of the organization, focusing on the things that matter (or strategic issues), identifying solutions, and reassessing not only the solutions but also the planning process.

While prior research indicates that there are common elements to strategic planning that we use as a foundation and backdrop to situate our communityengaged work, there is still debate about how to best create a strategic plan, including who should participate and the precise content of a plan (Poister \& Streib, 2005). By using this article, which is focused on the nuts and bolts of strategic planning via a state that recently underwent the process, the authors hope to contribute to the debate about best practices. The goal is to create a roadmap for a plan that is inclusive of diverse voices, outlines a mission and vision with action steps, and includes a concrete implantation map through using an interdisciplinary, community-engaged process. 


\section{U.S. Homeless Policy}

The strategic planning process, within which the authors participated in community-engaged research, was geared toward reducing the incidence of homelessness in Utah. Nationwide, homelessness is challenging U.S. communities to think outside the box and to create strategies that effectively help individuals step out of homelessness. While there are numerous definitions of what it means to be homeless, HUD defines homelessness as "individuals and families who lack a fixed, regular, and adequate nighttime residence," and the federal rule includes three additional categories of homelessness, including families that are about to lose their homes, unaccompanied youth and families with children, and those fleeing or attempting to flee domestic violence or abuse (Interim Final Rule, 2012). While stereotypes of individuals experiencing homelessness abound, homelessness does not discriminate based on gender, age, and race/ethnicity. In 2018, over seventy percent of those experiencing homelessness were over the age of twenty-four, about seventy-eight percent were non-Hispanic or Latino, sixty percent were male, and almost half were white (AHAR 2018).

Homeless programs exist at all levels - federal, state, and local - with approaches, resources, and success varying across communities. State policies and efforts differ across the country, with some taking more proactive approaches with a significant investment of financial resources and others taking a more devolutionary approach, placing responsibility on municipal or local governments. At the federal level, homeless programs are mostly regulated by the Continuum of Care Program within HUD. This program mandates that communities create collaborative bodies or networks comprised of crosssector actors who are expected to pool resources and create community-wide plans - the authors call these collaborative bodies CoC networks. While CoC networks compete for limited federal funding for local efforts through HUD's CoC Program, CoC networks are encouraged to diversify their revenues and secure support from other sources, including the state, foundations, and other private entities. Utah has three CoC networks: one that serves Salt Lake County (with the largest concentration of homeless population in the state); another that serves three counties (Utah, Summit, and Wasatch counties); and a third that serves the remaining, predominantly rural, counties.

\section{The Specific Study Context}

In 2018, the State of Utah legislature passed a law requiring the creation of a State Homeless Coordinating Committee (SHCC) comprised of directors or leaders of key state agencies and nonprofit groups with a responsibility to expend annual appropriations and designated homeless funds and engage in statewide coordination of homeless programs. In the spring of 2019, the legislature amended this statute and added the responsibility of this committee, creating a statewide strategic plan on homelessness. It was this amendment and new state policy that opened the opportunity for the authors of this study to engage in the process of drafting a strategic plan. 
The Utah Department of Workforce Services (DWS) Division of Housing and Community Development (the Division), as the administrative arm of the State Homeless Coordinating Committee (SHCC), was charged with searching for a group that could lead the process of drafting the statewide strategic plan. The authors were approached by an alum with connections to the Division about conducting the work and arranged for a meeting to discuss the parameters. Ultimately, we were hired to lead the process of building a strategic plan, and our research team consisted of two political science professors along with ten graduate research assistants. The research process commenced in mid-May 2019 and the data collection, analysis, and a majority of the report drafting were carried out over ten weeks. The following section describes the specific research process that was adopted to complete the strategic plan.

\section{Research Design \& Methods}

As previously noted, the process of leading the planning process and drafting the strategic plan for the State of Utah was a very fast exercise that involved many hours of research, data collection, conversations with stakeholders, taking notes, and more. We engaged in reflection in order to reconstruct and organize the process that we, as researchers, undertook to complete our task. In the research context, Mortari (2015) defines reflection as a process of elucidating "the epistemic acts developed in the midst of inquiry process" (p.1). This involves researchers, particularly in qualitative inquiry, thinking back and making sense of the steps taken in the research process. We also use Bryson's (2018) conceptual framework on the strategic change process to organize our process where possible.

Thus, the findings that we present in the following section are the results of both the reflexivity exercise and our intentional grounding of the steps we took in the Bryson (2018) work, which we ultimately organize in three phases (see Figure 1). In the first phase, we include the initial process of building a partnership with the State of Utah and the ingredients necessary to achieve an eventual contract to engage in strategic planning. In the second phase, we elaborate on the steps to conduct the actual strategic planning process. In the third and final phase, we cover our writing and drafting of the strategic plan and the experiences of getting the plan adopted.

\section{Findings: The Nuts \& Bolts of Developing a Strategic Plan}

\section{Phase 1: Establish Agreement}

\section{Step 1: Connect with the Community Partner}

Our expertise in homeless policy, experience in working with government agencies, and passion for community service helped us achieve a level of trust and legitimacy - enough for an alum of one of our graduate programs to approach us and to coordinate a meeting with the Division. The researchers' impression was that the Division saw it advantageous to engage and partner with university professors who could offer fresh perspectives, as outside agents of the homeless system, and who had the time and experience to engage an 


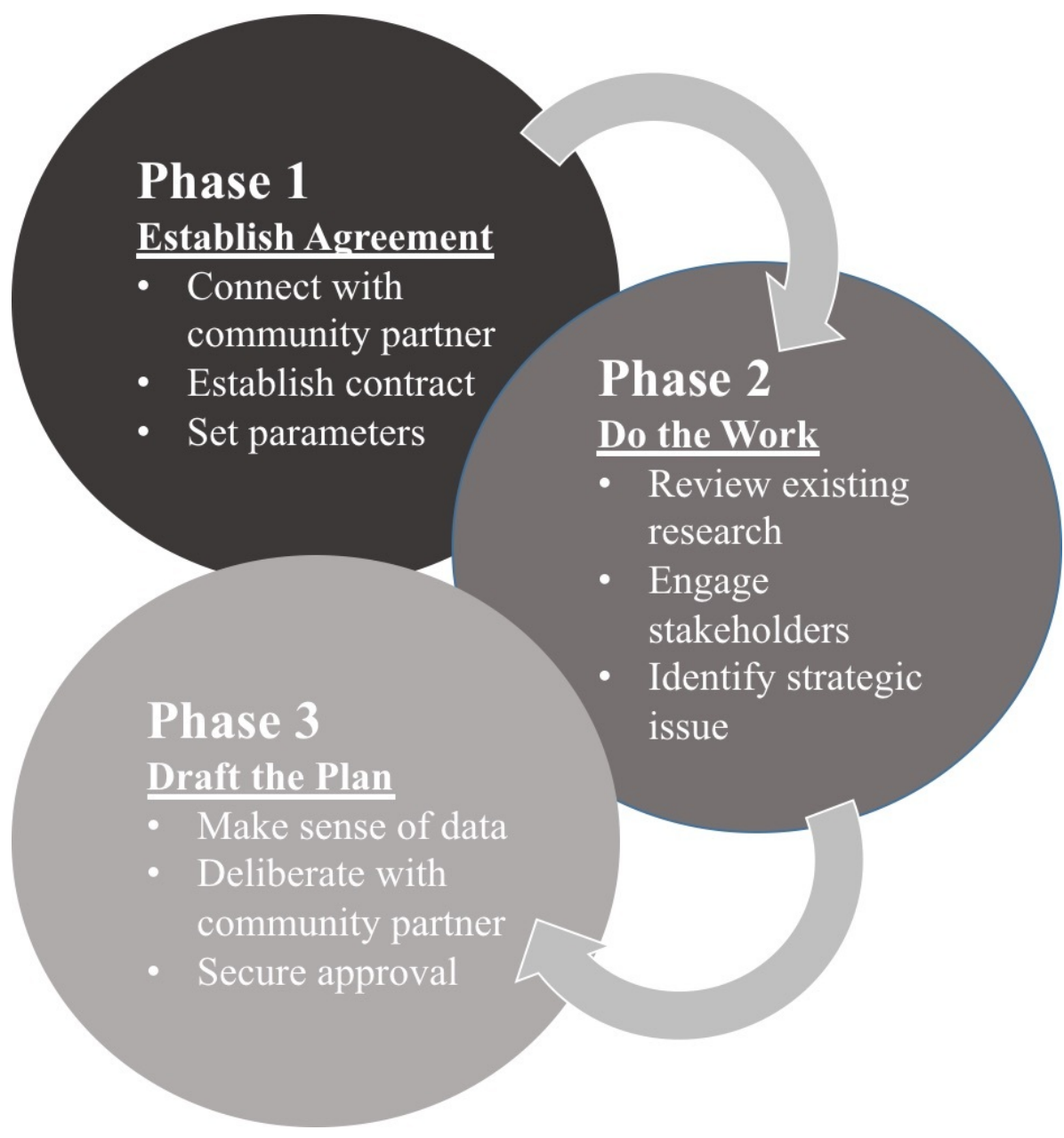

Figure 1: Strategic Change Phases

entire community to complete such an arduous effort. In other words, the Division was looking to contract out and hire a "planning team" that would be responsible for leading the process of developing a strategic plan and generating a draft of the actual plan. This choice is consistent with existing research that suggests that creating a planning team is important for centralizing the effort and ensuring that someone is responsible for shepherding the process (Bryson, 2018).

At the first meeting in April 2019, the Division conducted a presentation on the need for the strategic plan and the history of the State's mandate. This information was crucial to understanding the context or environment under which the strategic plan would be developed and implemented. We asked questions about the parameters of the project such as: was the strategic plan only focused on the homeless service system?; What was the timeline of the project?; Who would be the primary contact for the State?; What resources were available to execute the project?; Were key stakeholders aware of this plan and was there buy-in? It was in this initial meeting, for instance, that we learned about the tight timeline, that the Division would be the primary community partner, and that we became keenly aware of the important stakeholder groups that needed to be engaged in our process (see Figure 2). 


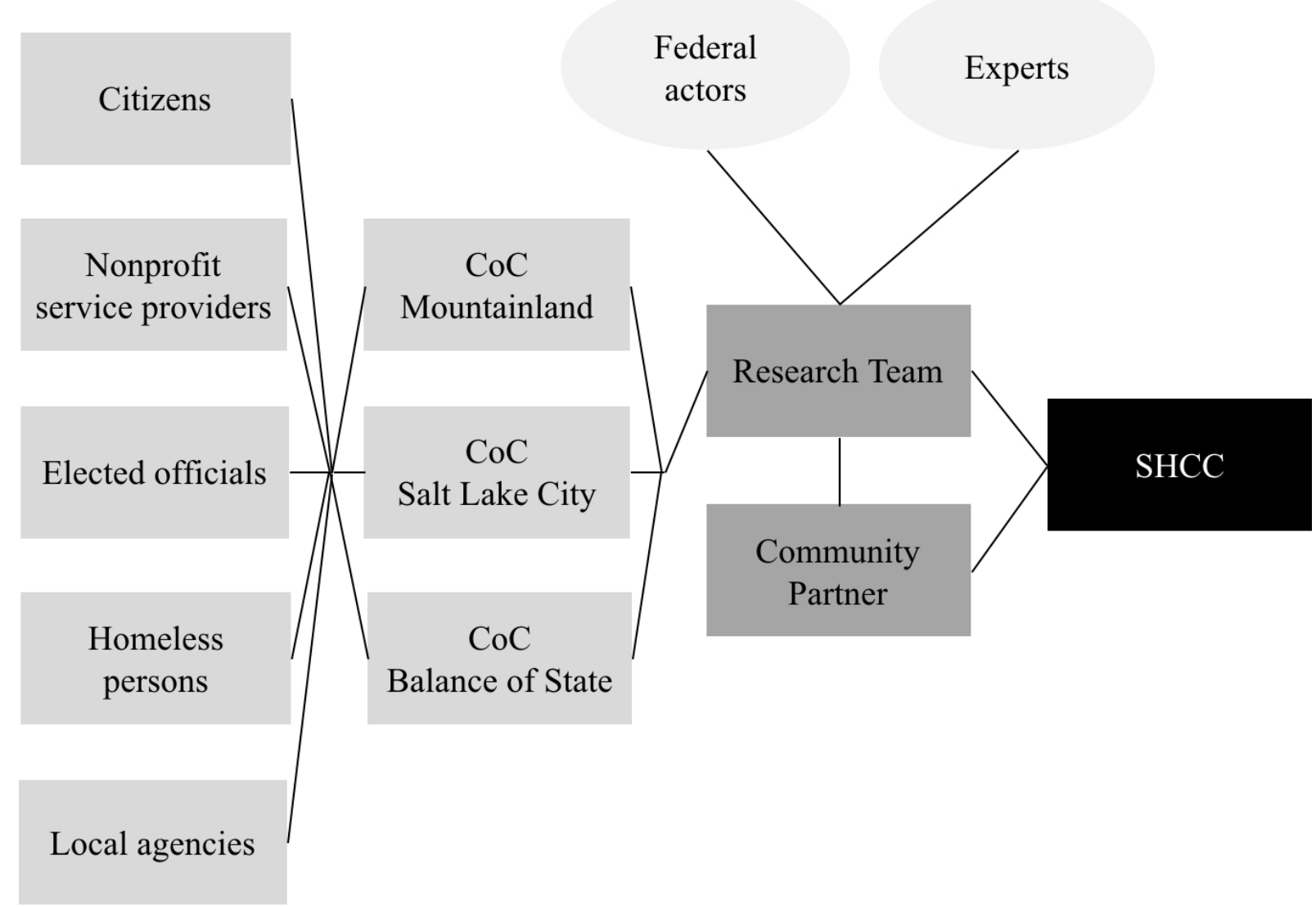

Figure 2: Stakeholder Input Map

\section{Step 2: Set the parameters and establish trust}

One of the critical components in successful collaboration is trust. In group settings, trust is buttressed by a sense among the collaborating partners of what they bring to the table and how they contribute to the overall success of the group. That basic trust is frequently lacking between representatives of the world of research and professionals moving in the world of practice. In the areas of public administration and public policy, the rift between academia and practice is smaller than in many other disciplines, but a healthy skepticism of what one can bring to the other frequently lurks in the background of nascent collaborations.

To overcome reservations about what an academic research team could bring to Utah's strategic planning process around homelessness, the team was helped in two ways. The first was the positive and longstanding reputation of the professional master programs that the researchers belonged to. A long list of distinguished and impactful alumni of these programs has left a residue of positive community action and a list of public and nonprofit sector contacts in Utah that the team was able to draw on.

Along with a positive institutional and professional reputation, the research team also had other trusted actors lent their credibility to the team at pivotal points, when decisions were made, when meetings needed to be called, and when information needed to be collected. The alum of the professional master 
program connected the community partner to the researchers and set up the initial in-person meeting to explore the possibility of the research team providing support for the strategic planning process.

Finally, a coordinator working for the community partner helped the research team organize the focus groups, urging local committees to accept the research team, to find diverse participants, and to select a date for the focus group in their location. Without these individuals being willing to invest their political and professional capital to vouch for the researchers, this communityengaged strategic planning process could not have happened. It would have taken much too long for the researchers to establish the type of personal relationships and trust needed to get the approvals, organizing, and funding to support this work; instead, they needed to rely heavily on their partners.

Throughout the community-engaged strategic planning process, ideas and suggestions by the community partner were clarified, considered by the research team, broken down into several tangible steps and proposals, presented to the community partner, and then negotiated to reach a viable way forward. Throughout this process, support from the community partner and its contacts was requested as needs were identified. This process was iterative; the community partner often had several ideas and preferences that it proposed to the research team, but that the research team felt needed to be discussed internally prior to creating a response and actionable way to meet the requests or suggestions.

The partnership was skewed, in terms of initiative, toward the community partner, with the research team mainly actively listening to distill needs and envision outcomes and priorities. The researchers then used their brainstorming capacity and wider reference frame to find viable ways forward, taking those expressed and desired goals into account. An area where the research team took the initiative was in underscoring the importance of early and inclusive stakeholder participation in the process of researching and drafting the plan. This was articulated to the community partner as a core value held by the research team and something the researchers viewed as pivotal in terms of the quality of the plan. The other real point of emphasis from the research team was in terms of drawing on an appropriate and efficient method to secure early and diverse stakeholder participation. The community partner saw this as valuable and this was evident in their support of the proposed budget, which included costs associated with traveling to all key communities across the State (i.e., per diem and hotel costs for the research team, and food for participants of focus groups).

As is often the case with large undertakings, particularly in politicallycontentious areas such as social policy, many goals, objectives, and needs are sought to be met with one solution, in this case with the strategic plan on homelessness for all of Utah. As is equally true in many cases, the list of what the community partner wanted the plan to do, establish, accomplish, and be used for was long. Homeless services and homelessness as a social issue had been a contentious topic in Utah for a while before the Legislature mandated 
the state coordinating committee on homelessness to develop a strategic plan. Sensing the many political pressures, needs, and challenges behind the mandate, along with a relatively tight timeline for getting the plan drafted, the researchers felt a strong need to drill down into the community partner's values, needs, and priorities.

The second meeting with the community partner, therefore, was to discuss the goals and objectives of the strategic plan as well as discuss politics, needs, challenges, and other relevant dynamics surrounding the development. For example, the community partner coordinated two key meetings that helped the team develop a better understanding of these dynamics. The first was a meeting with data management staff, who provided the authors with an overview and details of homelessness data in the State such as trends, issues, and needs, and ultimately provided the team with access to the data for analysis. The second meeting was with key political stakeholders, where the research team actively listened to a conversation about data sharing and data integration across the state to better understand the landscape of the problem. This meeting afforded an orientation to the political climate and a taste of the politics of homelessness in the state.

\section{Step 3: Establish the Contract}

Some of the concrete outcomes of the first two steps in phase 1 was a proposal on the process that the researchers recommended for developing the plan as well as an approximation of costs. The actual approval process for both the research process and the budget was a two-step approach where the community partner first had to view the budget as being in an approvable range with good motivation for allocated costs, and a second step of pitching the process and budget to the state committee that could authorize the action and spending. To save precious time, the researchers outlined the process, developed a rough draft budget and draft contract for the work while simultaneously trying to discern from the community partner what would be deemed approvable at the two stages. The difficulty of these simultaneous needs should not be understated. The community partner did not wish to restrict the researchers in terms of selecting the most effective method for getting the job done, but public organizations have limited budgets, and the partnership would only have one try at getting this project approved.

While we were not provided a proposal template, we chose to model our proposal based on standard grant proposal elements, including: 1) background, 2) scientific approach, 3) timeline, and 4) budget. For example, our scientific approach consisted of reviewing existing research, policies, and strategic plans, conducting focus groups with stakeholders across the state, and individually interviewing key stakeholders. We opted to not include a literature review as the subject of the study was well known and understood by both the funding agency and the research team. The Division reviewed the proposal, and with their initial thumbs-up, the proposal was sent for review and consideration by the SHCC at their upcoming meeting in mid-May 2019. We were invited to conduct a brief presentation before the SHCC that 
summarized the content of our written proposal into a few slides. With no questions asked by the SHCC, we received approval for both the proposal and budget. With this approval in hand, we now had approximately 10 weeks to produce a draft plan for review by the Division. Overall, this first phase correlates with Bryson's (2010) first two steps of initiating and agreeing on the planning process and identifying organizational mandates, including informal rules and political considerations.

\section{Step 4: Training the Next Generation of Community-Engaged Scholars and Practitioners}

In many ways, community-engaged research is the road less traveled in academia and there is a need for a critical mass in scholarship of this kind for it to gain wider acceptance and appreciation. Thus, as educators and researchers, the authors saw a rare but invaluable opportunity to train another generation of community-engaged researchers and practitioners within the strategic planning project. With a sense of trepidation at the sheer volume of work this would add for the researchers, but determined not to let an opportunity to have graduate students participate in hands-on community-engaged research on a very important topic in their state, the authors advertised graduate student work with the project. Ten students from professional master programs and the Ph.D. program in political science were selected and trained in focus group methodology and briefed on homeless policy. These students then joined the researchers driving across Utah in two- to four-person groups, helping with catering, taking notes on the focus group conversations and body language of participants, and debriefing in the car on the way back. The students learned quickly and were an invaluable asset to the research team, so much so that halfway through the planned focus groups they were facilitating, both under supervision and independently.

The research team's priority had been to make scheduling as easy as possible for the coordinator and local homeless coordinating committees that were pulling the focus group participants together. The research team had also offered to meet rural stakeholders and groups where the local homeless coordinating committee would normally meet in order to bridge the gap between rural and urban input. Because of the timing and location of the focus groups, the researchers and students had to stay in hotels overnight several times to make morning meetings in remote locations or to avoid driving back late at night. This added burden to the graduate students, who all had serious commitments in addition to being full-time students. One student worked as a police officer, one managed the Governor's mansion, and one student had twenty children, to mention a few. The enthusiasm with which the graduate students threw themselves into the community-engaged research was astounding, and it greatly enhanced the quality of the draft strategic plan itself. 
Phase 2: Do the Work

\section{Step 1: Study Formal Constraints: Existing State and Federal Policies, Reports and Publications}

The research team conducted a robust collection and review of existing state and federal policies, reports, and publications relating to individual and family homelessness. This initial step also included capturing the magnitude of the problem and trends for homeless populations and subpopulations by analyzing data from the Continuum of Care (CoC) Program of the U.S. Department of Housing and Urban Development. Performance of Utah CoCs was compared to national averages as well as to similar communities within states in the Western U.S. Census Region ${ }^{2}$. The western region was chosen because the State of Utah is situated within this region, offering the opportunity to compare data sources with most similar cases. This choice also reflected the team's limited time and resources - it was impossible to compare Utah's performance to every state in the country.

The team also collected and analyzed nine ${ }^{3}$ existing statewide strategic plans in other states, also using the Western U.S. Census Region as a sampling frame. The team found that all states except for two (Colorado and California) had existing statewide plans. These plans were used to decipher best practices and understand how other states were approaching the incidence of homelessness within their state, including the development of tested and effective interventions and strategies for engaging their state in collaborative governance.

\section{Step 2: Engage Stakeholders: Identifying Common Values \& Assessing the Local Environments}

The research team deliberated on how to approach the process of engaging stakeholders in focus group discussions, and after thoughtful discussion and debate, decided to adopt a collaborative governance lens. This approach seemed most fitting as the community partner and the state had an interest in developing a plan that was collaborative in nature. Ansell and Gash's (2008) "Model of Collaborative Governance," was specifically adopted and was used as a framework to develop a facilitation guide for the focus groups and interviews with key informants. The guide included questions about: 1) conditions in the community; 2) the process of working together and ways of improving coordination; 3) measuring impact and benchmarks; and 4) other topics of interest to the participants.

We coordinated and held an initial meeting with leaders of homeless policy and programs, specifically the leadership of the three CoC networks in Utah. The purpose of organizing this meeting was threefold. First, it was necessary to connect with individuals who were key to the team being successful in reaching diverse voices within their jurisdictions. The research team knew it would be

\footnotetext{
2 Region 4 or West Census Region includes: Alaska, Arizona, California, Colorado, Hawaii, Idaho, New Mexico, Montana, Oregon, Utah, Nevada, Washington, and Wyoming

3 States with statewide plans include: Alaska, Arizona, Hawaii, Idaho, Montana, Nevada, New Mexico, Oregon, Wyoming, Washington
} 
important to introduce themselves and ensure that these leaders had buy-in to the process adopted to achieve data collection, which would ultimately inform the draft of the strategic plan. Second, it was necessary to vet the facilitation guide and process for conducting the focus groups. With a tight deadline and no opportunity to conduct pilot testing, the research team quickly realized that an initial meeting with leadership would prove helpful in testing the content of the focus groups and the designed process. Lastly, this initial session was used to obtain important data and information on the inner workings of the $\mathrm{CoC}$ networks, the needs and challenges facing these communities, and advice and suggestions for carrying out the project.

To achieve broad inclusion of community voices and input, researchers organized and hosted focus groups across the entire State of Utah. The research team relied extensively on the staff of the community partner to do this, particularly in coordinating the focus groups in rural Utah. We were able to connect with the leadership of the two larger $\mathrm{CoC}$ networks, but since the community partner functioned as the administrative arm of the $\mathrm{CoC}$ network dedicated to rural communities (the third $\mathrm{CoC}$ network), the team relied on their help in reaching out to those communities. Because organizing so many individual focus groups in rural areas would be challenging with, for example, limited availability due to the short notice, the research team decided to open their calendar and work around the schedule of each local homeless coordinating committees (LHCC). The team adopted a "schedule and figure it out later" mentality to secure the participation of as many local communities as possible.

This process helped schedule focus groups with all communities except two, both of which were communities with inactive LHCCS, and one of which was a Native American reservation. Dissatisfied with having two communities possibly missing from the data collection efforts, the research team tapped into existing networks and connections with alums and other community organizations to find possible contacts in those areas. The team was successful in identifying an alum who lived in the Native American community and whom the research team had experience working with. The team reached out via email, coordinated a phone conversation, and secured this alum's help in coordinating a meeting with service providers, leaders of the tribe, and others with experience working with the homeless population in the area. The authors, however, were not successful in achieving contact with anyone in the remaining community. Thus, the team ultimately conducted focus groups with twelve out of thirteen LHCCs.

Overall, a total of 170 individuals representing nonprofit organizations, government, citizens, and other stakeholders participated in focus groups (see Table 1 for the demographic profile of participants).

The research team also found it important to engage with subject matter experts from federal agencies, since the federal law and federal programs relating to homelessness bear significant weight in Utah, with the existence of the three $\mathrm{CoC}$ networks and HUD CoC funding being a significant funding 
Table 1: Demographic Profile of Focus Group Participants

\begin{tabular}{|l|l|c|c|}
\hline & & $N$ & $\%$ \\
\hline \multirow{3}{*}{ Gender } & Male & 72 & $42 \%$ \\
\cline { 2 - 4 } & Female & 99 & $58 \%$ \\
\hline \multirow{3}{*}{ Race/Ethnicity } & White & 148 & $87 \%$ \\
\cline { 2 - 4 } & Nonwhite & 22 & $13 \%$ \\
\hline \multirow{5}{*}{ Constituency } & Government & 69 & $41 \%$ \\
\cline { 2 - 4 } & Nonprofit & 86 & $51 \%$ \\
\cline { 2 - 4 } & Education & 6 & $4 \%$ \\
\cline { 2 - 4 } & Citizen & 7 & $4 \%$ \\
\cline { 2 - 4 } & Other & 170 & $1 \%$ \\
\hline TOTAL & & 2 & $100 \%$ \\
\hline
\end{tabular}

source. The team considered it important to obtain the perspective of a HUD representative, who could speak to the $\mathrm{CoC}$ network approach, funding, and federal-state relations and thus, the team reached out and interviewed the HUD representative for the region. In this interview, the team learned about the history of the $\mathrm{CoC}$ program, an insider perspective on the workings of the federal agency overseeing federal homeless programs, and advice for understanding the possibilities of a state strategic plan and its relationship to the federal government. At the time, it was also learned that the U.S. Interagency Council on Homelessness (USICH), which is an organization comprised of the heads of federal agencies who collaborate on issues of homeless policy, had recently released its federal strategic plan on homelessness, entitled Home Together. The team contacted and secured an interview with the USICH representative for the State of Utah, and from this conservation learned about the new federal strategic plan and ways of aligning Utah's plan with the federal plan.

\section{Step 3: Transcribing and Analyzing Focus Groups and Interviews}

With the approval of focus group participants and all interviewees, conversations were recorded using a recording device. These recordings were transcribed and stored in a qualitative software: Nvivo 12.0. Detailed notes taken during the conversations were collected from researchers and graduate students assisting with focus groups, and these notes were also stored in the software. The research team used NVivo to study, code, and analyze focus groups and interviews. NVivo was chosen for its user-friendly platform and the research team's previous experience using the software, which was found to help conduct structured coding. Using a grounded approach, the researchers generated initial codes around the topics of interest. These were studied, and, after additional coding, themes were identified around existing services, service needs/gaps, ideas for measurement and benchmarks, and mission and vision for the state. 


\section{Phase 3: Draft the Plan}

\section{Step 1: Making Sense of the Data \& Identifying Strategic Issues}

After studying the results of the coded data independently, researchers met to discuss and make sense of the data. Keeping our initial agreement on the planning process, politics, and mandates in mind, we began to draft key elements: community needs or service gaps, ways of improving coordination, benchmarks and performance measures, and recommendations. We knew that these four components were expected to be a part of the plan, and thus we focused our energy and effort into writing these key pieces first. For example, regarding service gaps, we discussed what we each considered to be significant service gaps in the homeless service system based on the degree to which the issue was coded and/or discussed in focus groups. We wrote those impressions down to assess whether we were each in agreement or to cross-reference our interpretations. Where we departed, we engaged in deliberation to come to an agreement about whether pieces should move forward or eliminated from consideration and inclusion into the write-up.

\section{Step 2: Community-Engaged Draft Presentation and Stakeholder Reviews}

Once a full draft of the plan had been compiled, the researchers met with the community partner organization to get feedback. Each page of the draft report was reviewed individually and the community partner provided feedback on the content, the tone of the writing, and plausible implications for the plan's adoption and implementation. The research team took the community partner's comments and requests for revision, and reconvened separately to further process and develop the plan. This review-and-revision process was conducted in several iterations, with each review occurring in face-to-face meetings with the community partner. Other stakeholders whom the community partner wanted to have participate in the review process took part in these meetings in real-time, but through web-conference calls. Among these stakeholders were experts from the federal level of the homeless services system.

After the community partner and invited experts provided feedback on the draft plan, the research team made extensive revisions. Most of the revisions were in the way that the information was organized and visually presented, but also in terms of highlighting how the state plan on homeless policy and service provision mapped onto the existing federal plan.

At this point, it was also very clear that the community partner felt it needed concrete benchmarks for improvement of the current service output and its impact on the homeless populations in Utah. The research team was very reticent to place a definitive number or percentage increase or decrease benchmarks for the specific efforts proposed in the plan. The researchers asked the community partner if the national average, a regional Western average benchmark, or a benchmark internal to Utah based on the CoC average in the state would be a better basis for comparison. One of the challenges within, as well as outside of, Utah is that the homeless populations are numerous and quite different in how their homelessness manifests and what is needed 
to decrease homelessness within these populations. Another challenge is that the conditions of homelessness, as well as the homeless populations, vary drastically between rural and urban communities, different localities, different seasons, and among CoCs and states. This makes it less helpful to compare averages or even concrete percentage increases or decreases to benchmark and measure progress.

It had also become clear that data collection and funding based on available data in the state of Utah had fundamentally skewed needs assessments and resource allocations away from small and rural communities in favor of large and urban communities. The focus groups had posed questions about what benchmarks and comparison groups each community would prefer to have as it sought to change and hopefully improve homeless service provision moving forward. Almost without exception, each local community wanted to measure its progress against itself, looking honestly at prior performance, setting valuebased and context adapted goals for the community, and then measuring progress towards those local priorities and goals each year.

The local communities themselves were aware of the great variation in need and resources, as well as in the shifting homeless populations in the states. They welcomed a more structured model upon which they would be able to formulate goals and measure their progress. There was no reluctance, to the researchers' surprise, to work to improve performance or better meet the needs of the homeless in their community. There was, however, a strong sense that local coordinating committees needed help, expertise, sharing of best practices amongst themselves, more access to resources, and recognition from centrallylocated policy-makers that rural areas and small towns around Utah were struggling to meet these needs and needed support.

\section{Step 3: Collaborating with the Community-Partner in the Review Process}

Once the draft had gone through this initial review and revision process, it was resubmitted to the community partner. After several reviews, the community partner scheduled a presentation by the researchers of the drafted plan to the state homeless coordinating committee. The researchers focused on outlining the community engagement that the draft plan was built on, showing participation rates, demographics, and the number of focus groups. The researchers also outlined the organization of the plan and key recommendations. The community partner then took over in terms of fleshing out how the content of the plan responded to the mandate that the state coordinating committee had been charged with, some shifts that the plan implied, and possible implementation routes. The committee members made few comments and asked that the community partner and researchers distill the plan further, primarily by adding more graphic representations and decreasing its wordiness.

The community partner put the revised draft plan out for public comment for a two week-period. Once the comment period had closed, the research team received the public comments and were urged to consider them as ways 
of improving plan. These comments were incorporated and the plan revised to simplify its wording, reduce wordiness, and add visual representations of how benchmarks, measures, and goals in the Utah strategic plan were to work together. The plan then underwent another review and graphic design process with the community partner organization and was finally sent to the state homeless coordinating committee for review and a vote of approval.

\section{Step 4: Navigating the Approval Process \& Setting Up Implementation}

The Utah State Homeless Coordinating Committee voted to adopt the Utah Strategic Plan on Homelessness, with only one substantive change, in October 2019. The community partner and the researchers felt that the nearunanimous support for the plan was closely linked to how the plan had been produced: through a research-led community-engagement process grounded in a collaborative governance model. That the hours, days, and mileage the research team and the graduate students had put into meeting stakeholders where they were and honestly inviting input was clear at the Utah Homeless Summit, hosted by the community partner a few weeks after the plan was adopted. There was a lot of positive discussion and a sense of ownership of the state strategic plan among the many stakeholders represented at that summit. The discussions were not directed at what the plan stated or why the content of the plan was what it was; rather, stakeholders discussed what they were already doing to move the needle on the measures they found most relevant locally and how they could learn from other locales about implementing new efforts. The researchers were there, invited by the community partner, to present the plan and discuss its recommendations. Along with the positive feedback the researchers and community partner received about the process of communityengaged research and strategic planning, the researchers walked away from this experience with a deepened respect for the ability of the community partner to read the political landscape and meet different stakeholders' competing needs in an integrated way.

\section{Conclusion}

Much has been written about the theory of strategic planning and the scholarship has suggested conceptual ways of engaging in this management process. Less has been written about how to actually go about the process of leading and writing a strategic plan and the experiences that practitioners and researchers alike undergo in working on strategic planning. This article addressed this need by documenting and outlining the processes that an interdisciplinary community-engaged research team used to research and draft a statewide strategic plan on homelessness. This work has nascent implications for both theory and practice.

From a theoretical perspective, this community-engaged project and the reflective process that the authors used to reconstruct and organize the steps taken to engage in strategic planning confirms the practical value of key elements of strategic planning found in the prior research. This includes the importance of an initial agreement on the parameters of the work, the 
engagement of key stakeholder groups, identifying strategic issues, and drafting a set of actions that address the strategic issues and encompass a vision for change (Bryson, 2018). In addition, this study fills an important gap in extant research on the realities of doing strategic planning and documented experiences from the field on how to successfully manage community-engaged change processes.

From a practitioner perspective, this study offers a detailed account of how to lead strategic planning processes in government and nonprofit organizations as well as how to structure participation when conducting this type of work. This study provides some important lessons learned and ways of managing challenges involved in conducting large-scale collaborative work. Additionally, this work captures a strategic planning process that is unique in scale and scope - we found few statewide plans on homelessness, and the process outlined here may be helpful for states interested in developing plans of this scale.

We understand that while this study makes an important contribution to the existing scholarship, our research has some limitations. Our study is explicitly focused on homeless policy and some of the experiences we document here may not necessarily translate to other policy fields, specifically the engagement of specific stakeholder groups (CoC leadership or SHCC body) and their influence on the development of the strategic plan. Future work should consider documenting the strategic planning process in other fields and then assessing the overlap and commonalities with case studies such as this one. 


\section{References}

Bryson, J. (2011). Strategic Planning for Public and Nonprofit Organizations: A Guide to Strengthening and Sustaining Organizational Achievement (4th ed., Bryson on Strategic Planning Series).

Bryson, J. (2018). Strategic planning for public and nomprofit organizations: A guide to strengthening and sustaining organizational achievement (Fifth). Jossey-Bass.

Bryson, J., Berry, F. S., \& Yang, K. (2010). The state of public strategic management research: A selective literature review and set of future directions. The American Review of Public Administration, 4O(5), 495-521. https://doi.org/10.1177/0275074010370361

Interim Final Rule, 2506-AC29 C.F.R, Homeless Emergency Assistance and Rapid Transition to Housing: Continuum of Care Program (2012).

Mortari, L. (2015). Reflectivity in Research Practice: An Overview of Different Perspectives. International Journal of Qualitative Methods, 14(5), 160940691561804. https://doi.org/10.1177/ $\underline{1609406915618045}$

Poister, T. H., \& Streib, G. (2005). Elements of strategic planning and management in municipal government: Status after two decades. Public Administration Review, 65(1), 45-56. https://doi.org/ 10.1111/j.1540-6210.2005.00429.x

The U.S. Department of Housing and Urban Development. (2018). The 2018 Annual Homeless Assessment Report (AHAR) to Congress. 